\section{JURNAL ABDIMAS

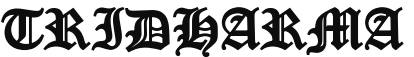

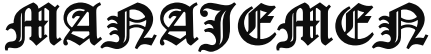

\title{
MANAJEMEN MERAIH SUKSES SEJATI DENGAN BERWIRAUSAHA DI ERA PANDEMI PADA IBU-IBU PKK RT 02 RW 04 RANGKAPAN JAYA BARU DEPOK
}

\author{
Endah Mawarny, Ifa Nurmasari, Septi Rostika Anjani, \\ Neneng Tita Amalya, Hamdi Supriadi \\ Dosen Ekonomi Fakultas Ekonomi Universitas Pamulang \\ Email dosen01747@unpam.ac.id, dosen01550@unpam.ac.id, dosen01699@unpam.ac.id, \\ dosen01751@unpam.ac.id, dosen01021@unpam.ac.id
}

\begin{abstract}
ABSTRAK
Jumlah penduduk yang besar merupakan aset bagi suatu bangsa dalam meningkatkan kualitas hidupnya. Namun laju pertumbuhan penduduk yang tidak diimbangi dengan peningkatan pada bidang lain, seperti ekonomi dan bidang lainnya berakibat menyempitnya lapangan pekerjaan yang pada akhirnya akan meningkatkan jumlah pengangguran. Permasalahan banyaknya pengangguran semakin berat ketika pandemi covid 19 melanda bangsa kita. Akhirnya untuk bertahan hidup dan menghidupi keluarga beberapa ibu rumah tangga bekerja apa saja untuk membantu perekonomian keluarga. Tujuan PKM ini adalah untuk memberikan pengetahuan tentang bagaimana menjadi wirausaha sukses pada ibu-ibu PKK RT 2, RW 4, Rangkapan Jaya Baru Pancoran Mas, Depok.

Metode yang digunakan pada PKM ini adalah dengan memberikan pengetahuan, berbagi pengalaman dan memberikan motivasi tentang wirausaha kepada ibu-ibu PKK RT 2, RW 4, Rangkapan Jaya Baru Pancoran Mas, Depok. Kegiatan dilakukan dengan cara online, yaitu melalui google meet dan juga offline. Kegiatan offline dilaksanakan di rumah Ibu RT 2, RW 4, Jalan Masjid Al Hukama, Rangkapan Jaya Baru, Pancoran Mas, Depok. Untuk kegiatan offline dilaksanakan dengan tetap mematuhi protocol Kesehatan. Acara offline dipandu oleh mahasiswa Unpam dengan menyaksikan materi yang disampaikan secara online.

Hasil dari kegiatan PKM ini, memperlihatkan bertambahnya pengetahuan IbuIbu PKK tentang wirausaha. Selain itu terlihat adanya antusias untuk mulai berwirausaha bagi yang belum dan menambah semangat yang sudah berwirausaha untuk mengembangkan bisnisnya.
\end{abstract}

Kata kunci : wirausaha, pandemi, PKK

\begin{abstract}
ABSTRAC
A large population is an asset for a nation in improving its quality of life. However, the rate of population growth which was not matched by increases in other fields, such as the economy and other fields, resulted in a narrowing of employment which in turn would increase the number of unemployed. The problem of unemployment is getting heavier when the Covid 19 pandemic hits our nation. Finally, to survive and support the family, some housewives work anything to help the family economy. The purpose of this PKM is
\end{abstract}




\section{JURNAL ABDIMAS

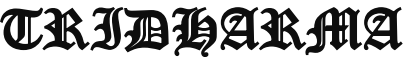 AtA}

to provide knowledge about how to become successful entrepreneurs in PKK RT 2, RW 4, Rangkap Jaya Baru Pancoran Mas, Depok.

The method used in this PKM is to provide knowledge, share experiences and provide motivation about entrepreneurship to PKK RT 2, RW 4, Rangkap Jaya Baru Pancoran Mas, Depok. Activities are carried out online, namely through google meet and offline. Offline activities were carried out at the house of Ibu RT 2, RW 4, Jalan Masjid Al Hukama, Rangkap Jaya Baru, Pancoran Mas, Depok. Offline activities are carried out while adhering to health protocols. The offline event was hosted by Unpam students by watching the material presented online.

The results of this PKM show the increased knowledge of PKK mothers about entrepreneurship. In addition, there is enthusiasm to start entrepreneurship for those who have not and increase the enthusiasm for those who are already entrepreneurial to develop their business.

\section{Keywords: entrepreneurship, pandemic, PKK}

\section{PENDAHULUAN}

Jumlah penduduk yang besar merupakan aset bagi suatu bangsa dalam meningkatkan kualitas hidupnya. Namun demikian laju pertumbuhan penduduk yang tidak diimbangi dengan peningkatan pada bidang lain, seperti ekonomi dan bidang lainnya berakibat menyempitnya lapangan pekerjaan yang pada akhirnya akan meningkatkan jumlah pengangguran. Permasalahan banyaknya pengangguran semakin berat ketika pandemi covid 19 melanda bangsa kita. Akhirnya untuk bertahan hidup dan menghidupi keluarga beberapa ibu rumah tangga bekerja apa saja untuk membantu perekonomian keluarga.

Pengetahuan pada bidang kewirausahaan nampaknya dapat menjadi alternatif kaum ibu / bapak yang sampai saat ini usahanya masih serabutan, agar dapat memperoleh penghasilan yang jelas, mapan, dan terkelola dengan baik melalui suatu usaha yang menghasilkan produk tertentu di rumah. Usaha semacam itu disebut home industry (industri rumah), yang bila berkembang harapannya mampu pula menciptakan lapangan kerja bagi masyarakat di sekitarnya. Salah satu cara untuk mengembangkan perekonomian di Indonesia adalah masyarakat harus merubah pola fikirnya untuk menjadi seorang entrepreneur, dan bukan hanya menjadi seorang entrepreneur yang biasa biasa saja, akan tetapi harus bisa menjadi seorang entrepreneur atau seorang pengusaha yang sukses agar bisa memberikan lapangan pekerjaan yang banyak, bukan hanya bisa bermanfaat atas diri sendiri tetapi dapat juga bermanfaat bagi orang lain yang membutuhkan.

Menurut DR. IR. Eddy Soeryanto Soegoto, Entrepreurship atau kewirausahaan adalah usaha kreatif yang dibangun berdasarkan inovasi untuk menghasilkan sesuatu yang baru, memiliki nilai tambah, memberi manfaat, menciptakan lapangan kerja dan hasilnya berguna bagi orang lain. Sedangkan Pengusaha adalah orang yang dapat dikategorikan sebagai wiraswasta atau wirausaha (teori ekonomi modern). Bila usahanya stagnan atau tidak berkembang maka pengusaha tersebut disebut sebagai wiraswasta sedangkan bila usahanya tumbuh, berkembang dan maju maka pengusaha tersebut disebut sebagai wirausaha.

Pemberdayaan Kesejahteraan Keluarga (PKK) sebagai wadah kegiatan wanita mempunyai peranan dalam membantu program pemerintah melalui gerakannya yang bertujuan mewujudkan keluarga sehat, sejahtera, maju dan mandiri. PKK mempunyai peran yang sangat strategis dalam memberdayakan keluarga 


\section{JURNAL ABDIMAS

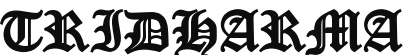

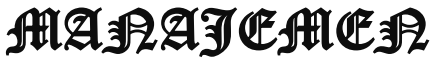

terutama perempuan sebagai motor penggeraknya.

\section{RUMUSAN MASALAH}

Dengan mempertimbangkan latar belakang yang telah dijelaskan diatas kami berinisiatif untuk mengadakan Kegiatan Pengabdian Kepada Masyarakat untuk ibuibu PKK RT 2, RW 4, Rangkapan Jaya Baru Pancoran Mas, Depok. Kegiatan ini dilakukan dengan berbagi pengetahuan, pengalaman dan motivasi tentang berwirausaha.

\section{TUJUAN PELAKSANAAN}

1. Memberikan pengetahuan kepada ibuibu PKK RT 2, RW 4, Rangkapan Jaya Baru Pancoran Mas, Depok mengenai apa itu wirausaha.

2. Berbagi pengalaman kepada ibu-ibu PKK RT 2, RW 4, Rangkapan Jaya Baru Pancoran Mas, Depok mengenai wirausaha.

3. Memberikan motivasi kepada ibu-ibu PKK RT 2, RW 4, Rangkapan Jaya Baru Pancoran Mas, Depok untuk mulai berwirausaha dan mengembangkan usahanya bagi yang sudah.

\section{TINJAUAN PUSTAKA}

\section{Pengertian Wirausaha}

Wirausaha berasal dari dua suku kata, wira dan usaha. Wira mempunyai arti sebagai pejuang, pahlawan, berbudi luhur, manusia unggul, berwatak agung dan gagah berani. Di lain sisi, usaha merupakan sebuah perbuatan atau amalan, berbuat sesuatu dan bekerja. Oleh karena itu, secara harfiah makna dari wirausaha adalah sebuah pejuang dalam melakukan suatu pekerjaan. Menurut Kamus Besar Bahasa Indonesia (KBBI), wirausaha merupakan orang yang pandai atau berbakat dalam memahami produk baru, menentukan cara produksi baru, menyusun operasi untuk mengadakan produk baru hingga mengatur permodalan dan pemasarannya. Melalui beberapa pengertian diatas, kita dapat mengambil kesimpulan bahwa wirausaha merupakan seseorang yang mempunyai kemampuan dalam menciptakan dan menerapkan cara kerja teknologi dan produk baru dengan meningkatkan efisiensi dan memperoleh keuntungan yang sebesar-besarnya.

\section{Manfaat Wirausaha}

Dengan berwirausaha, banyak hal positif yang bisa kita dapatkan :

a. Menentukan penghasilan sendiri.

Ketika berwirausaha, kita menjadi bos atas diri sendiri. Ketika ingin hasil yang banyak, maka kita harus bekerja lebih giat. Kita yang menentukan sendiri target pendapatan kita.

b. Mengembangkan potensi diri.

Jika kita berbisnis sendiri, kita bisa lebih bebas dalam mengeksplorasi dan mengembangkan kemampuan diri. Tidak ada yang menghalangi kita untuk melakukan apapun, kecuali kita sendiri yang tidak mau mencobanya.

c. Melakukan apa yang disukai.

Saat berbisnis, kita punya kesempatan untuk melakukan pekerjaan yang kita sukai. Kita bisa menjalankan usaha yang sesuai hobi.

d. Melatih mental sebagai pemimpin.

Sekecil apapun usaha yang kita rintis, kita langsung menjadi seorang pemimpin atas bisnis kita. Kita akan belajar banyak hal, mulai dari mengambil keputusan, mendelegasikan pekerjaan, menyelesaikan masalah, dan lainnya.

e. Menciptakan perubahan.

Keuntungan menjadi wirausaha adalah kita berkesempatan untuk menciptakan perubahan. Kita harus bisa berinovasi dan menghadirkan sesuatu yang baru bagi dunia.

f. Membantu membuka lapangan kerja.

Kita berkontribusi dalam mengurangi angka pengangguran. Semakin besar bisnis kita, semakin banyak lapangan kerja yang bisa dibuka.

g. Wawasan bertambah banyak 


\section{JURNAL ABDIMAS

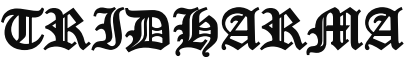 \\ AtA:}

Menjadi wirausaha, mau tak mau kita harus mempelajari banyak hal. Kita harus tahu bagaimana cara memanajemen keuangan, membuat strategi marketing, memimpin anak buah, melayani pelanggan, dan lain-lain.

h. Relasi semakin luas.

Kita akan bertemu dengan banyak orang ketika berbisnis, mulai dari konsumen, sesama pebisnis, investor, sampai aparatur pemerintah. Koneksi kita harus luas agar kita bisa lebih mudah dalam memasarkan produk, mengembangkan bisnis, menjalin kerja sama, dan juga mengurus perizinan usaha.

i. Waktu lebih fleksibel.

Waktu kita menjadi lebih fleksibel, karena kita sendiri yang menentukan jam kerja kita. Terlebih lagi jika bisnis kita sudah punya sistem yang baik, kita tidak perlu mengawasinya setiap saat. Sebab bisnisnya bisa terus berjalan, walaupun kita sedang tidak berada di tempat usaha.

\section{Kiat Menjadi Wirausaha}

Menjadi seorang pejuang dalam mendirikan usaha, sudah sepatutnya seorang wirausaha memiliki beberapa ciriciri dan karakterstik :

a. Berprestasi.

Penggerak utama yang memotivasi untuk berwirausaha adalah kebutuhan untuk berprestasi. Kebutuhan merupakan keinginan atau dorongan dalam diri personal yang memotivasi ke arah pencapaian tujuan.

b. Jujur.

Sebuah perusahaan yang memiliki pimpinan dan karyawan yang jujur akan lebih berkembang dan sukses.

c. Disiplin.

Sikap disiplin mampu menggerakkan semangat dan motivasi untuk menjalankan usaha sehingga dapat mencapai target.

d. Kreatif dan Inovatif.

Wirausaha yang kreatif dan inovatif akan membawa perusahaan sukses berkembang sesuai zaman dalam menghadapi pasar.

e. Berkomitmen Tinggi.

Komitmen merupakan suatu karakter yang memegang teguh prinsip yang telah disepakati. Pada umumnya orang akan lebih memilih bekerja sama dengan orang yang berkomitmen.

f. Mandiri dan Realistis.

Sebagai seorang yang mempelopori sebuah usaha, maka seorang wirausaha adalah orang yang mandiri dalam melakukan sesuatu. Selain itu sikap realistis dalam membaca realita disekitarnya merupakan karakter seorang wirausaha.

g. Terampil.

Seorang wirausaha harus mampu mencari dan menangkap peluang yang datang, berkomunikasi dengan siapapun, menangani masalah apapun, dan mampu bekerja sama dengan pihak lain.

h. Futuristik.

Sebagai penggerak roda usaha, wirausaha memiliki kemampuan perencanaan dan berpikir ke depan. Seorang wirausaha mampu mencari dan mengantisipasi segala hal yang boleh jadi terjadi di masa yang akan datang.

i. Cerdas Finansial

Dalam menjalankan usaha pada wirausahawan harus memiliki pemikiran kreatif dan inovatif untuk mendapatkan hasil yang maksimal agar dapat meminimalisir kendala atau hambatan dalam menjalankan usahanya.

\section{Tips Menjadi Wirausaha Sukses}

Berikut adalah tips yang bisa membantu untuk dapat menjadi pengusaha yang sukses.

a. Pengusaha sukses itu bekerja keras dan tekun.

Memerlukan kerja keras dan konsisten sehingga tidak mudah menyerah ketika mendapatkan tantangan dalam menjalankan usaha.

b. Berani menantang diri sendiri. 


\section{JURNAL ABDIMAS

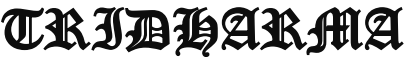

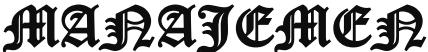

Seorang pengusaha harus siap menghadapi tantangan. Seorang pengusaha harus gesit dalam mencari tantangan berikutnya untuk menghadapi apa yang menjadi visi kita.

c. Lakukan karena Passion.

Semua yang dilakukan berdasarkan kesenangan akan terasa lebih ringan dan bisa menjadi sebuah cara yang tepat untuk memulai bisnis kita. Dengan passion pengusaha tidak akan pernah lelah untuk bekerja berjam-jam dan masih bersemangat untuk mendapatkan ide-ide bisnis kreatif baru yang tidak pernah dibayangkan sebelumnya.

d. Berani mengambil resiko.

Mengambil keputusan dengan mempertimbangkan resiko terkecil dari pilihannya adalah hal yang perlu dibiasakan dan ini merupakan salah satu cara menjadi pengusaha sukses. Sehingga calon pengusaha dapat ditentukan dari cara pandangnya menyelesaikan masalah.

e. Pengusaha sukses itu percaya diri.

Percaya akan kemampuan diri akan menghilangkan rasa ketidakpastiaan yang seringkali menjadi ketakutan penguasaha diawal memulai berwirausaha. Kita harus yakin dengan kemampuan, pengalaman dan ilmu yang kita miliki.

\section{METODE PELAKSANAAN}

Pada Kegiatan Pengabdian Kepada Masyarakat (PKM) ini dilakukan dengan memberikan pengetahuan, pengalaman serta memotivasi bagaiamana memulai, menjadi wirausaha yang baik, yang dapat menyesuaikan diri dengan perkembangan jaman serta dapat memanfaatkan perkembangan teknologi.

Kegiatan PKM ini ditujukan untuk ibu-ibu PKK Jalan Masjid Al-Hukama RT 2 RW 4 Rangkapan Jaya Baru, Pancoran Mas, Depok. Sebelum PKM dilaksanakan, dilakukan survei ke lokasi Ibu-ibu PKK. Kemudian dilanjutkan dengan pelaksanaan penyampaian materi pada hari Senin, 7 Desember 2020. Kegiatan ini dilaksanakan dari pukul 09.00 sampai dengan pukul 12.00 siang. Setelah acara selesai, dilakukan evaluasi mengenai kegiatan tersebut.

Acara ini dilaksanakan secara offline dan online. Untuk acara offline, kegiatan dilaksanakan di rumah ibu RT 2 RW 4 Jalan Masjid Al-Hukama Rangkapan Jaya Baru, Pancoran Mas, Depok. Acara dilaksanakan dengan tetap mengikuti aturan protokol kesehatan covid 19. Kegiatan dipandu oleh mahasiswa untuk mengikuti acara secara online. Sedangkan untuk kegiatan online dilaksanakan dengan menggunakan google meet.

\section{HASIL DAN PEMBAHASAN}

Pelaksanaan PKM dilakukan dengan tahapan berikut :

1. Persiapan acara

Persiapan dilakukan pukul 08.30 untuk memastikan segala sarana dan prasarana yang menunjang kegiatan seminar online dan kegiatan offline berjalan dengan baik. Dosen berkoordinasi dengan mahasiswa yang memandu jalannya kegiatan secara offline.

2. Registrasi peserta

Registrasi peserta dilakukan secara online dan offline.

3. Pembukaan acara dan pembacaan ayat suci Al Quran

Acara dibuka oleh MC, dilanjutkan dengan pembacaan ayat suci Al Quran oleh mahasiswa untuk menambah khitmat acara.

4. Sambutan dari ibu-ibu PKK, diwakilkan oleh ibu Sarliah, S. Farm., Apt. selalu Ketua RT 2 RW 4 Rangkapan Jaya Baru, Pancoran Mas Depok.

5. Sambutan dari Ketua PKM

Ketua PKM, Ibu Endah Mawarny, S.Pd.I., M.A mewakili dosen dan mahasiswa memberikan sambutan pada acara tersebut.

6. Penyampaian Materi

Pemberian materi disampaikan oleh dosen-dosen Universitas Pamulang.

7. Sesi tanya jawab Ada 3 penanya yang menyampaikan 


\section{JURNAL ABDIMAS

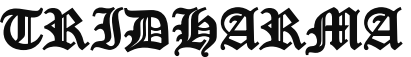

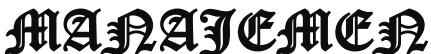

P-ISSN 2715-7105, E-ISSN 2716-070X

Jurnal ABDIMAS Vol. 2, No. 1, Januari 2021,Hal (54-60)

@Prodi Manajemen Fakultas Ekonomi Universitas Pamulang

Email: abdimasjurnal.unpam@ gmail.com Telp: (021) 741-2566 pertanyaan dengan dipandu oleh mahasiswa. Kemudian pertanyaan dijawab langsung secara on line oleh oleh pemateri.

8. Penyerahan sourvernir / cinderamata Pemberian cinderamata dilakukan secara offline, diwakilkan oleh mahasisawa yang memandu jalannya kegiatan tersebut.

9. Penutupan dan pembacaan doa penutup. Pada pukul 11.30 acara ditutup dan dilanjutkan dengan doa bersama sebagai rasa syukur atas pelaksanaan acara yang berjalan lancar dan harapan semoga materi yang telah disampaikan pada acara tersebut dapat bermanfaat.

10. Foto Bersama.

Foto Bersama dilakukan baik secara online maupun offline

Pada hari ketiga kegiatan PKM, yaitu setelah dilakukan kegiatan inti PKM, dilakukan evaluasi tentang kegiatan yang telah dilaksanakan. Panitia mendatangi kediaman Ibu RT 2 RW 4 mengevaluasi kegiatan yang telah dilaksanakan.

\section{KESIMPULAN DAN SARAN \\ Kesimpulan}

Berdasarkan pelaksanaan kegiatan Pengabdian Kepada Masyarakat yang dilaksanakan di Jalan Masjid Al-Hukama RT 2 RW 4 Rangkapan Jaya Baru, Pancoran Mas Depok, pada hari Minggu sampai Selasa, tanggal 6-8 Desember 2020 dapat diambil kesimpulan bahwa :

1. Secara umum kegiatan Pengabdian Kepada Masyarakat dapat terlaksana dengan baik dan mendapat dukungan dari pihak ibu-ibu PKK RT 2 RW 4 Jalan Masjid Al-Hukama Rangkapan Jaya Baru, Pancoran Mas Depok.

2. Materi yang disampaikan oleh narasumber bermanfaat bagi ibu-ibu PKK RT 2 RW 4 Jalan Masjid AlHukama Rangkapan Jaya Baru, Pancoran Mas Depok.

\section{Saran}

Mengingat besarnya manfaat kegiatan Pengabdian Kepada Masyarakat ini, maka selanjutnya perlu:

1. Sebaiknya seorang wirausaha dapat menyesuaikan diri dengan keadaan yang terjadi meskipun dalam kondisi pandemi covid 19. Selain itu seorang enterpreneur harus dapat memanfaatkan teknologi yang ada seperti sekarang untuk membantu dalam proses pemasarannya.

2. Seorang entrepreneur sebaiknya selalu mengikuti pelatihan dan seminar untuk selalu memperbarui pengetahuan yang dimilikinya.

3. Perlu dilakukan kerjasama lebih lanjut antara UNPAM dan ibu-ibu PKK RT 2 RW 4 Jalan Masjid Al-Hukama Rangkapan Jaya Baru, Pancoran Mas Depok.

\section{DAFTAR PUSTAKA}

Nurmasari, I., Supriadi, H., Mawarny, E., Amalya, N. T., \& Anjani, S. R. (2020). MANAJEMEN PROFESIONAL GURU DALAM KUALITAS MENDIDIK SEBAGAI UPAYA PENINGKATAN MUTU SUMBER DAYA MANUSIA. JURNAL LOKABMAS KREATIF, 1(2), 52-55.

Pasaribu, V. L. D., Susanti, F., \& Hartuti, E. T. K. (2019). Memotivasi Siswa dan Siswi SMK Letris Indonesia di Dalam Menentukan Pilihan Untuk Melanjutkan Pendidikan Atau Bekerja Setelah Lulus Sekolah. Jurnal Pengabdian Dharma Laksana, 1(2), 161-172.

Pasaribu, V. L. D., Agrasadya, A., Shabrina, N., \& Krisnaldy, K. (2020). MENJADI ENTERPRENEUR MUDA YANG MEMILIKI JIWA LEADERSHIP UNTUK MENGHADAPI MASA DEPAN. Abdi

Laksana, 1(1).

Pasaribu, V. L. D., Elburdah, R. P., Sudarso, E., \& Fauziah, G. (2020). PENGGUNAAN MANAJEMEN WAKTU TERHADAP PENINGKATAN PRESTASI BELAJAR DI SMP ARAISIYAH. Jurnal ABDIMAS Tri Dharma Manajemen, 1(1). 


\section{JURNAL ABDIMAS

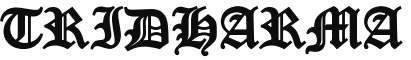

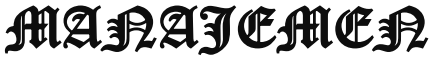

P-ISSN 2715-7105, E-ISSN 2716-070X

Jurnal ABDIMAS Vol. 2, No. 1, Januari 2021,Hal (54-60)

@ Prodi Manajemen Fakultas Ekonomi Universitas Pamulang

Email: abdimasjurnal.unpam@ gmail.com Telp: (021) 741-2566
Pasaribu, V. L. D., Sulaiman, S., Sutiman, S., Thaharudin, T., \& Purnomo, B. Y. (2020). PENGENALAN LETAK POSYANDU TERDEKAT DIKELURAHAN PISANGAN DENGAN MANAJEMEN PEMASARAN REVOLUSI 4.0 UNTUK MENINGKATKAN PENGETAHUAN MASYARAKAT LETAK DAN FUNGSI POSYANDU TERDEKAT PADA KELURAHAN

PISANGAN. DEDIKASI PKM, I(1), 105-110.

Pasaribu, V. L. D., Oktrima, B., Prabowo, B., Arianto, N., \& Haryoko, U. B. (2020). PROGAM PENDAMPINGAN DAN PENYELENGGARAAN PENDIDIKAN ANAK PADA USIA DINI TERHADAP PRESTASI BELAJAR DILINGKUNGAN RT 020 RW 009. KEL GIRI PENI. KEC WATES. YOGYAKARTA. JURNAL LOKABMAS KREATIF, 1(1), 71-75.

Suryana, Kewirausahaan Full Edision, Salemba Empat, Jakarta, 2013

Sumber Dari Internet:

https://entrepreneurcamp.id/keuntunganmenjadi-wirausaha/ dilihat pada tanggal 17 Oktober 2020 pukul 20.05 WIB

https://gobiz.co.id/pusatpengetahuan/pengusaha-sukses/ dilihat pada tanggal 17 Oktober 2020 pukul 19.40 WIB

https://saintif.com/pengertian-wirausaha/ dilihat pada tanggal 17 Oktober 2020 pukul $19.30 \mathrm{WIB}$

https://www.futuready.com/artikel/lifestyle -leisure/apa-peran-ibu-pkk-pembinaankesejahteraan-keluarga/ dilihat pada tanggal 17 Oktober 2020 pukul $20.30 \mathrm{WIB}$

\section{DOKUMENTASI FOTO KEGIATAN}

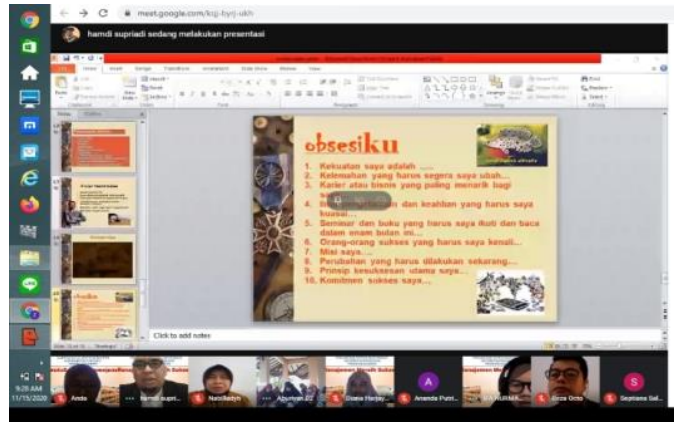

Penyampaian materi oleh dosen Unpam

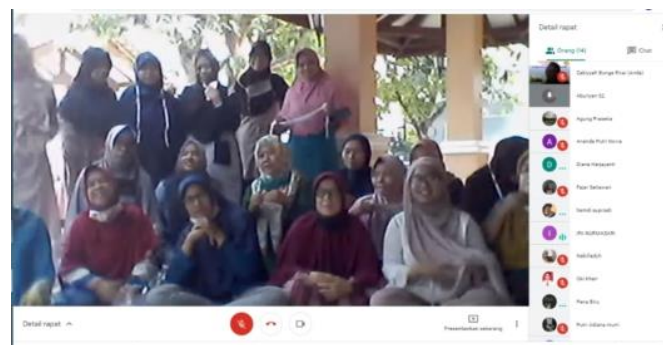

Peserta offline di rumah ibu RT 2 RW 4

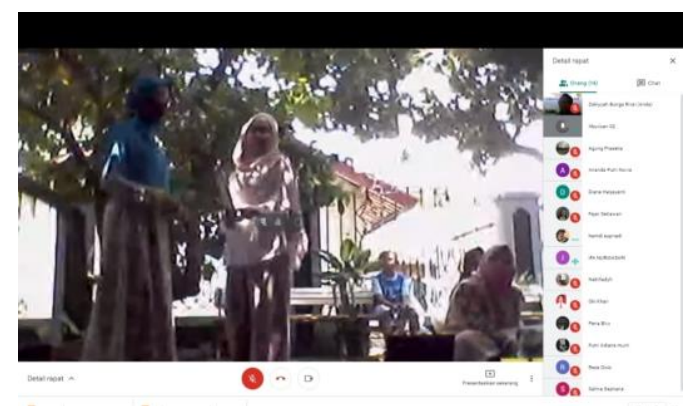

Penyerahan kenang-kenangan oleh Perwakilan mahasiswa 